\title{
Reliability analysis of nose wheel assy ATR 72-500
}

\author{
Fajar Khanif Rahmawati ${ }^{1, *}$, Sri Mulyani \\ Program Studi Teknik Dirgantara Sekolah Tinggi Teknologi Adisutjipto \\ Email Korespondesni: *fajar.khanif@gmail.com
}

\begin{abstract}
Aircraft reliability is one aspect that needs to be considered in aircraft operation. The reliability program has been implemented in aircraft maintenance policies, especially for aircraft with high utilization. The reliability program could measure the level of reliability of a component. The nose wheel assy on the ATR 72-500 aircraft is one of the components that has repeated defects, so that a reliability analysis could be performed. The analysis is carried out with a Weibull distribution with data of failure time. From data processing, it was obtained the value of Beta $(\beta)=3.810$ which means that the failure characteristic that occurs is early wear out. In addition, the reliability value of $R(t)$ was also obtained for every failure time. The value and graphic shows that the trend is decreasing with failure time of component .From the calculation with the Weibull distribution, it also showed the Mean Time to Failure (MTBF) reaches 454.014 hours.
\end{abstract}

Keywords: Nose Wheel Assy, Maintenance, Weibull,Reliability

\section{Pendahuluan}

Teknologi dirgantara dengan salah satu produknya yaitu pesawat terbang merupakan salah satu teknologi yang terus mengalami perkembangan. Dengan melibatkan banyak aspek dari disiplin ilmu, teknologi pesawat terbang semakin menunjukan kemajuan. Hal ini dapat diketahui dari semakin sempurnanya produk - produk pesawat terbang yang diproduksi dengan menerapkan teknologi - teknologi yang dapat meningkatkan kenyamanan pengguna pesawat terbang.

Selain teknologi dari pesawat terbang yang terus dikembangkan, kebijakan - kebijakan dalam perawatan pesawat terbang pun juga mengalami perkembangan. Sejarah dalam perawatan pesawat terbang diawali dengan munculnya metode dalam maintenance program and evaluation yaitu mengenai MSG (Maintenance Steering Group). Hal ini merupakan awal perhatian bahwa selain teknologi yang terus berkembang, perawatan dari teknologi tersebut juga terus dikembangkan. Bermula dari MSG-1 hingga MSG-3 program perawatan pesawat terbang semakin memperhatikan banyak aspek yang dapat menyempurnakan program perawatan tersebut.

Salah satu perkembangan dari program perawatan adalah adanya reliabilty program yang diterapkan hingga saat ini. Reliability atau keandalan pada suatu pesawat terbang merupakan salah satu tujuan yang dapat tercapai dengan pelaksanaan kegiatan perawatan. Sebagaimana definisi maintenance adalah suatu 
proses untuk memastikan bahwa suatu sistem dapat terus bekerja pada tingkat keandalam dan keamanan yang telah dirancang [7].

Reliability dapat didefinisikan sebagai kemungkinan (probability) sebuah sistem atau komponen dapat melakukan fungsi tertentu pada periode waktu tertentu saat digunakan dalam kondisi operasi tertentu [3]. Reliability dapat diartikan sebagai suatu keandalan atau kemampuan untuk diandalkan [8]. Analisa mengenai reliability pada setiap komponen dari pesawat terbang menjadi penting untuk dilakukan jika komponen tersebut mengalami kerusakan yang berulang dalam kurun waktu tertentu. Nose Wheel Assy pada pesawa ATR 72-500 merupakan salah satu komponen yang selalu digunakan dalam proses taxing, take off, landing, dan parking. Kerusakan berupa worn out sering kali ditemukan, sehingga analisa mengenai reliability dari nose wheel assy ini perlu untuk dilakukan.

\section{Metode Penelitian}

Penelitian ini menggunakan metode kuantitatif dengan menggunakan distribusi Weibull. Metode kuantitatif yang digunakan pada penelitian ini merupakan proses menemukan pengetahuan dengan data berupa angka sebagai alat untuk menganalisis keterangan mengenai apa yang ingin diketahui[6]. Weibull analysis merupakan metode yang digunakan untuk meningkatkan usia data atau komponen nuklir, dental research, advertising [1]. Sehingga distribusi Weibull dapat digunakan dalam upaya analisa penngkatan keandalan dari komponen nose wheel assy. Proses pelaksanaan penelitian ini sebagaimana diilustrasikan pada Gambar 1.

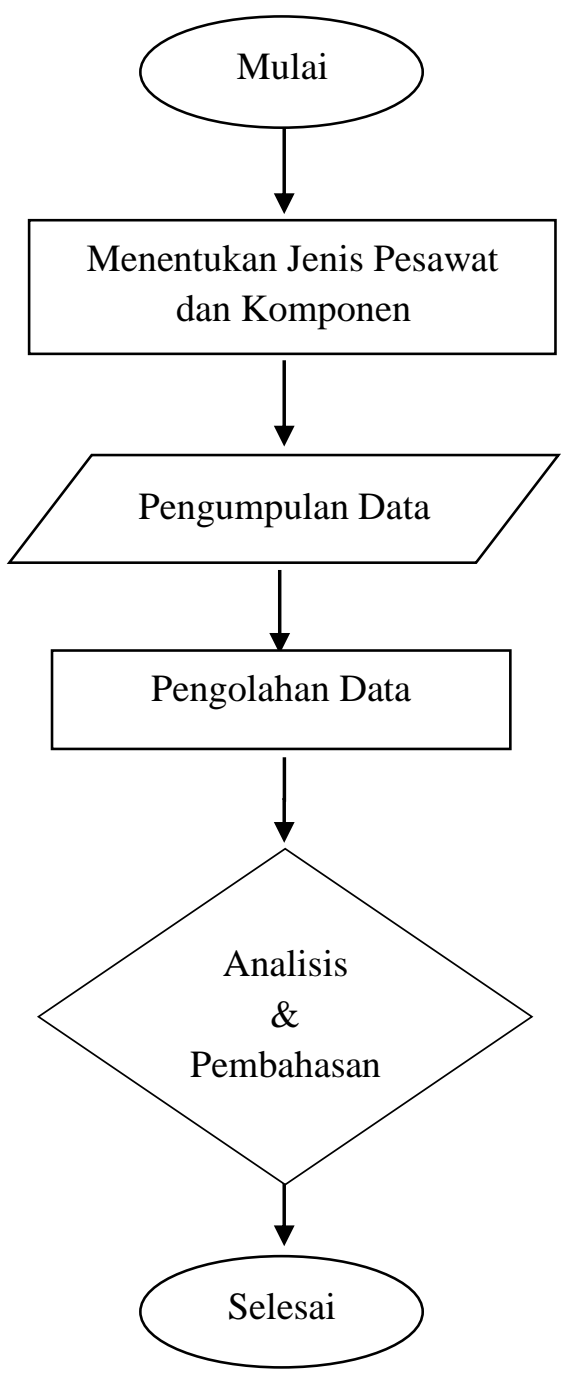

Gambar 1. Flowchart Penelitian 
Penjelasan mengenai flowchart penelitian adalah sebagai berikut :

- Mulai, adalah tahap menentukan latar belakang pengambilan tema penelitian dan merumuskan rumusan masalah.

- Menentukan jenis pesawat dan komponennya, adalah tahap menentukan jenis pesawat dan komponen yang akan dijadikan objek penelitian. Dalam penelitian ini jenis pesawat yang digunakan untuk objek penelitian adalah ATR 72-500, dan komponennya adalah Nose Wheel Assy.

- Pengumpulan data meliputi: Data Komponen, adalah usia komponen yang diperoleh dari status komponen nose wheel assy.

- Pengolahan data, dilakukan dengan distribusi Weibull untuk memperoleh nilai keandalan dan juga usia rata - rata komponen.

- Analisa dan Pembahasan, merupakan tahap menganalisa hasil pengolahan data terhadap kegiatan perawatan yang dapat dilakukan pada nose wheel assy untuk meningkatkan keandalannya.

- Selesai, merupakan tahap memberikan kesimpulan dari hasil penelitian yang telah dilakukan.

Data yang diperlukan dalam penelitian ini adalah data kerusakan atau maintenance defect yang terjadi pada nose wheel assy pesawat ATR 72-500 yang melaksanakan kegiatan perawatan di PT. Pelita Air Service. Data yang diperoleh terjadi dalam kurun waktu 2 (dua) tahun yaitu Maret 2017 sampai dengan Desember 2018[5]. Adapun data kegagalan yang terjadi pada nose wheel assy pesawat ATR72-500 adalah sebagaimana dalam Tabel 1 [5].

Tabel 1. Kegagalan Nose Wheel Assy ATR72-500

\begin{tabular}{|c|c|c|c|c|c|}
\hline No & $\begin{array}{c}\text { Pat } \\
\text { Number }\end{array}$ & $\begin{array}{c}\text { Installed } \\
(\text { Hrs })\end{array}$ & $\begin{array}{c}\text { Removed } \\
(\mathrm{Hrs})\end{array}$ & $\begin{array}{c}T S I \\
(H r s)\end{array}$ & Reason \\
\hline 1 & C-15848 & 19808,34 & 20199,01 & 390,67 & Nose wheel tyre worn out \\
\hline 2 & D-44110 & 20199,01 & 20798,36 & 599,35 & Please check nose wheel tyre \\
\hline 3 & A-96344 & 20798,36 & 21320,73 & 522,37 & $\begin{array}{l}\text { During post flight found nose wheel worn } \\
\text { out (LH\& RH) }\end{array}$ \\
\hline 4 & D-44095 & 21320,73 & 21696,4 & 375,67 & $\begin{array}{c}\text { Req. Replace nose wheel tyre both due } \\
\text { worn out }\end{array}$ \\
\hline 5 & D-44098 & 21696,4 & 22250,62 & 554,22 & Req. Nose wheel assy replacement \\
\hline 6 & D-43816 & 22250,62 & 22536,35 & 285,73 & Both nose wheel assy replacement \\
\hline
\end{tabular}

Data yang akan digunakan dalam distribusi weibull adalah data usia komponen selama dipasang pada pesawat ATR 72-500 atau disebut dengan TSI (Time Since Installation). Data inilah yang akan digunakan sebagai data failure time pada perhitungan.

\section{Hasil dan Pembahasan}

Pengolahan data dengan distribusi weibull dilakukan dengan membuat peringkat data dari yang terkecil hingga terbesar untuk menetapkan posisi plot untuk waktu kegagalan $(t)$, sumbu dan ordinat fungsi-fungsi yang akan ditentukan dalam bentuk bilangan desimal. Selanjutnya dilakukan perhitungan adjusted rank dengan persamaan Benard's sebagaimana rumus 1. Perhitungan ini akan memberikan pengaruh terhadap peningkatan nilai $\operatorname{eta}(\eta)$.

$$
\text { Adjusted Rank }=i=\frac{(\text { Reverse } r a n k) \times(\text { Previous Adjusted Rank })+(N+1)}{(\text { Reverse } \text { Rank })+1}
$$

Dimana: $\mathrm{N}$ merupakan number of sample.

Setelah menghitug adjusted rank selanjutnya dilakukan perhitungan median rank, perhitungan dilakukan menggunakan persamaan benard's pada rumus 2 .

$$
\text { Benard's Median Rank }=\frac{(\mathrm{i}-0,3)}{(\mathrm{N}+0,4)}
$$

Dimana: i merupakan adjusted rank 
Hasil dari perhitungan adjusted rank dan median rank sebagaimana pada Tabel 2.

Tabel 2. Hasil Perhitungan adjusted rank dan median rank

\begin{tabular}{cccc}
\hline $\begin{array}{c}\text { Failure Time } \\
(\mathrm{t})\end{array}$ & $\begin{array}{c}\text { Adjusted } \\
\text { Rank }\end{array}$ & $\begin{array}{c}\text { Reverse } \\
\text { Rank }\end{array}$ & $\begin{array}{c}\text { Median } \\
\text { rank }\end{array}$ \\
\hline 285,73 & 1 & 6 & 0,109375 \\
375,67 & 2 & 5 & 0,265625 \\
390,67 & 3 & 4 & 0,421875 \\
522,37 & 4 & 3 & 0,578125 \\
554,22 & 5 & 2 & 0,734375 \\
599,35 & 6 & 1 & 0,890625 \\
\hline
\end{tabular}

Setelah menentukan nilai median rank terhadap failure time. Kemudian dengan menentukan logaritma natural dari failure time setiap kegagalan maka akan diperoleh nilai dari variabel $\mathrm{x}$ dan $\mathrm{y}$ sebagaimana rumus 3 dan 4 .:

$$
\begin{aligned}
& \mathrm{X}=\operatorname{In}\left[\ln \left(\frac{1}{1-\text { Median Rank }}\right)\right] \\
& \mathrm{Y}=\mathrm{In} \text { (failure time) }
\end{aligned}
$$

Hasil perhitungan variabel $\mathrm{x}$ dan y sebagaimana pada Tabel 3 .

Tabel 3. Hasil Perhitungan Variabel X dan Y

\begin{tabular}{cccccccc}
\hline $\mathrm{i}$ & $\mathrm{t}$ & $\begin{array}{c}\text { Median } \\
\text { Rank }\end{array}$ & $\mathrm{X}_{\mathrm{i}}$ & $\mathrm{Y}_{\mathrm{i}}$ & $\mathrm{X}_{\mathrm{i}}, \mathrm{Y}_{\mathrm{i}}$ & $\mathrm{X}_{\mathrm{i}}{ }^{2}$ & $\mathrm{Y}_{\mathrm{i}}{ }^{2}$ \\
\hline 1 & 285,73 & 0,109375 & $-2,155616006$ & 5,655047309 & $-12,19011049$ & 4,646680366 & 31,97956007 \\
2 & 375,67 & 0,265625 & $-1,175270415$ & 5,928711098 & $-6,967838754$ & 1,381260549 & 35,14961529 \\
3 & 390,67 & 0,421875 & $-0,601543551$ & 5,967863214 & $-3,58992963$ & 0,361854644 & 35,61539134 \\
4 & 522,37 & 0,578125 & $-0,147287035$ & 6,258376149 & $-0,921777667$ & 0,021693471 & 39,16727202 \\
5 & 554,22 & 0,734375 & 0,281917795 & 6,31756172 & 1,781033072 & 0,079477643 & 39,91158608 \\
6 & 599,35 & 0,890625 & 0,794336831 & 6,395845735 & 5,08045583 & 0,630971001 & 40,90684266 \\
& $\sum$ & $-3,003462381$ & 36,52340522 & $-16,80816764$ & 7,121937673 & 222,7302675 \\
\hline
\end{tabular}

Jumlah $\left(\sum\right)$ dari masing-masing variabel yang diperoleh akan digunakan pada persamaan least squares sehingga dapat menentukan nilai dari konstanta A dan B dengan menggunakan rumus 5 dan 6.

$$
\begin{aligned}
& \mathrm{B}=\frac{\sum_{i=1}^{n} x i \cdot y i-\frac{\sum_{i=1}^{n} x i \cdot \Sigma_{i=1}^{\eta} y i}{n}}{\sum_{i=1}^{n} x^{2}-\frac{\left(\sum_{i=1}^{n} i^{2}\right.}{n}} \\
& A=\bar{Y}-B \cdot \bar{X}
\end{aligned}
$$

Hasil perhitungan konstanta B adalah 0,26245765 sedangkan hasil perhitungan konstanta A adalah 6,218614484 .

Perhitungan selanjutnya adalah menghitung koefisien korelasi (r) untuk mengukur kekuatan hubungan linear dua variabel. Nilai koefisien korelasi yang diharapkan mendekati 1 (satu) agar sebaran distribusi data tepat pada garis lurus dan diketahui bahwa korelasi masing-masing parameter dekat dan benar. Koefisien korelasi dihitung dengan rumus 7.

$$
\mathrm{r}=\frac{\sum_{\mathrm{i}=1}^{\mathrm{n} X i . Y i-}-\frac{\sum_{i=1}^{\mathrm{n}} \mathrm{X} \Sigma_{i=1}^{\mathrm{n}} \mathrm{Yi}}{\mathrm{n}}}{\sqrt{\left(\sum_{\mathrm{i}=1}^{\mathrm{n}} \mathrm{Xi}^{2}-\frac{\left(\sum_{i=1}^{\mathrm{n}} \mathrm{Xi}\right)^{2}}{\mathrm{n}}\right)\left(\sum_{i=1}^{\mathrm{n}} \mathrm{Yi}^{2}-\frac{\left(\sum_{i=1}^{\mathrm{n}} \mathrm{Yi}\right)^{2}}{\mathrm{n}}\right)}}
$$


Hasil dari perhitungan koefisien korelasi adalah 0,979. Sedangkan koefisien determinan dapat ditentukan dengan mengkuadratkan koefisien korelasi yang telah diperoleh sehingga diperoleh koefisien determinasi sebesar 0,959. Berdasarkan hasil yang diperoleh maka dapat diketahui bahwa koefisien korelasi positif mendekati 1(satu) pada distribusi data yang merupakan keadaan dimana $\mathrm{Y}$ cenderung meningkat dan $\mathrm{X}$ meningkat, serta hubungan masing-masing parameter adalah dekat dan benar.

Untuk melanjutkan pengolahan data dengan distribusi weibull maka pengujian goodness of fit perlu dilakukan untuk menentukan nilai Mann's (M). Pada analisa ini akan dibanding nilai Mann's (M) dengan nilai $F_{\text {crit }}$ yang diperoleh dari tabel $F$. Apabila nilai $M>F_{\text {crit }}$ maka tidak dapat dianalisis oleh distribusi weibull dan jika $\mathrm{M}<\mathrm{F}_{\text {crit }}$ maka data dapat dianalisa dengan distribusi weibull. Untuk menentukan nilai Mann's (M) digunakan rumus 8.

$$
\mathrm{M}=\frac{k_{1} \sum_{i=k_{1}+1}^{r-1}\left[\left(\ln t_{i+1}-\ln t_{i}\right) / M_{i}\right]}{k_{2} \sum_{i=1}^{k_{1}}\left[\left(\ln t_{i+1}-\ln t_{i}\right) / M_{i}\right]}
$$

Dimana:

$$
\begin{aligned}
k_{1} & =\left\lfloor\frac{r}{2}\right\rfloor \\
k_{2} & =\left\lfloor\frac{r-1}{2}\right\rfloor \\
\mathrm{r} & =\text { Jumlah kegagalan } \\
Z_{i} & =\ln \left[-\ln \left(1-\frac{i-0.5}{n+0.25}\right)\right] \\
M_{i} & =Z_{i+1}-Z_{i}
\end{aligned}
$$

Hasil perhitungan untuk mencari nilai Mann's (M) sebagaimana pada Tabel 4.

Tabel 4. Hasil Perhitungan Data Nilai Variabel Terhadap Pengujian Mann's

\begin{tabular}{ccccccc}
\hline $\mathrm{i}$ & $\mathrm{t}$ & $\ln \mathrm{ti}$ & $\mathrm{Zi}$ & $\mathrm{Mi}$ & $\ln \mathrm{i}+\mathrm{i}-\operatorname{lnti}$ & $\ln +\mathrm{i}-\ln \mathrm{i} / \mathrm{Mi}$ \\
\hline 1 & 285,73 & 5,655047 & $-3,4011$ & 1,133314 & 0,2736638 & 0,241472154 \\
2 & 375,67 & 5,928711 & $-2,26779$ & 0,547691 & 0,0391521 & 0,07148582 \\
3 & 390,67 & 5,967863 & $-1,7201$ & 0,375816 & 0,2905129 & 0,77301941 \\
4 & 522,37 & 6,258376 & $-1,34428$ & 0,29353 & 0,0591856 & 0,201634136 \\
5 & 554,22 & 6,317562 & $-1,05075$ & 0,246256 & 0,078284 & 0,317896557 \\
6 & 599,35 & 6,395846 & $-0,8045$ & 0,804498 & $-6,3958457$ & $-7,950103203$ \\
\hline
\end{tabular}

Hasil yang diperoleh nilai Mann's $(\mathrm{M})$ sebesar 1,2 dan selanjutnya dibandingkan dengan nilai $\mathrm{F}_{\text {crit }}$ diperoleh dari tabel F. Nilai $F_{\text {crit }}$ diperoleh dari tabel distribusi $F$ dengan terlebih dahulu menentukan:

Nilai derajat kebebasan pembilang

$k_{1}=2 \times 3$

$k_{1}=6$

Nilai derajat kebebasan penyebut

$k_{2}=2 \times 2,5$

$k_{2}=5$

$\mathrm{F}_{\text {crit } 0,056,5}=4,95$

Maka diperoleh hasil perhitungan pengujian Mann's tersebut dengan nilai $\quad \mathrm{M}<\mathrm{F}_{\text {crit }}$ maka data kegagalan dai nose wheel assy pada ATR 72-500 dapat dianalisis menggunakan distribusi weibull. Parameter untuk mengukur keandalan dalam distribusi weilbull adalah parameter Beta $(\beta)$ dan eta ( $\eta)$. Beta ( $\beta$ ) merupakan parameter bentuk yang merupakan determinasi pada weibull line dari data yang diperoleh. Nilai beta $(\beta)$ diperoleh menggunakan rumus 


$$
\begin{aligned}
& \beta=\frac{1}{B} \\
& \beta=\frac{1}{0,26245765} \\
& \beta=3,810
\end{aligned}
$$

Berdasarkan hasil nilai beta ( $\beta$ ) diketahui bahwa nilai parameter beta ( $\beta$ ) lebih besar dari 1 namun kurang dari 4, maka parameter bentuk kegagalan yang mengakibatkan terjadinya kegagalan komponen

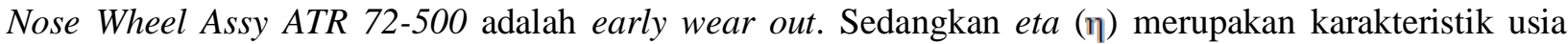
komponen dimana komponen tersebut akan mengalami kegagalan. Perhitungan untuk memperoleh nilai eta $(\eta)$ adalah sebagaimana rumus 10 .

$$
\begin{aligned}
& \eta=e^{A} \\
& \eta=2,718281828^{6,218614484} \\
& \eta=502,0072103=502,007
\end{aligned}
$$

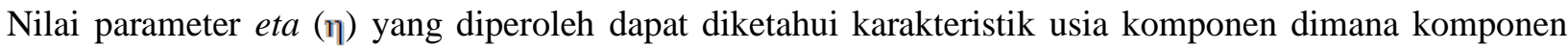
akan mengalami kegagalan adalah pada saat komponen telah mencapai usia pemakaian 502,007 hours.

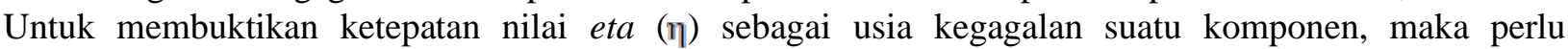
dilakukan perhitungan mean time to failure (MTTF). Hal ini dikarenakan jika beta ( $\beta$ ) lebih besar dari

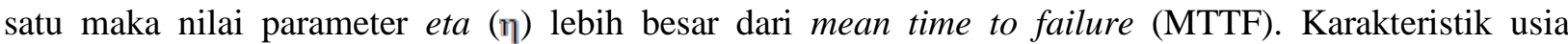
komponen akan mengalami kegagalan akan diperoleh pada perhitungan MTTF. Untuk dapat menentukan nilai MTTF maka terlebih dahulu untuk mencari nilai gamma $\Gamma(\mathrm{x})$ dengan rumus 11.

$$
\begin{aligned}
& x=\left(1+\frac{1}{\beta}\right) \\
& x=1,26245765
\end{aligned}
$$

Dengan menggunakan tabel fungsi Gamma diperoleh nilai gamma $\Gamma(1,26245765)=0,9044$. Untuk mendapatkan nilai MTTF dapat digunakan rumus 12.

$$
\begin{aligned}
& \text { MTTF }=\eta \cdot \Gamma\left[1+\frac{1}{\beta}\right] \\
& \text { MTTF }=454,014 \text { hours }
\end{aligned}
$$

Nilai MTTF (mean time to failure) 454,014 hours menyatakan usia rata - rata pemakaian komponen sampai dengan mengalami kegagalan. Nilai MTTF yang diperoleh juga menunjukan bahwa berdasarkan nilai parameter beta $(\beta)$, yaitu jika nilai beta $(\beta)$ lebih besar dari satu maka nilai MTTF lebih kecil dari nilai eta $(\eta)$. Nilai keandalan dari setiap komponen yang mengalami kegagalan dapat dihitung dengan fungsi keandalan distribusi weibull sabagaimana rumus 13 .

$R\left(t_{1}\right)=e^{-\left(t_{1} / \eta\right)^{\beta}}$

Hasil perhitungan fungsi keandalan sebagaimana pada Tabel 5.

Tabel 5. Nilai Reliability $\mathrm{R}(\mathrm{t})$

\begin{tabular}{cc}
\hline $\begin{array}{c}\text { Failure Time } \\
(\mathrm{t})\end{array}$ & $\mathrm{R}(\mathrm{t})$ \\
\hline 285,73 & 0,613237794 \\
375,67 & 0,525751227 \\
390,67 & 0,512426317 \\
522,37 & 0,409019823 \\
554,22 & 0,387321488 \\
599,35 & 0,358532361 \\
\hline
\end{tabular}


Keandalan dapat didefinisikan sebagai probabilitas suatu sistem dapat berfungsi dengan baik untuk melakukan tugas pada kondisi tertentu dan dalam selang waktu tertentu pula [13]. Hasil perhitungan menunjukan keandalan setiap komponen dari usia 285,73 hours sampai dengan 599,35 hours yang menunjukan trend menurun seiring dengan bertambahnya usia komponen sebagaimana pada Gambar 2 . Hasil ini juga menunjukan bahwa semakin lama alat tersebut beroperasi maka keandalan komponen semakin menurun [11].

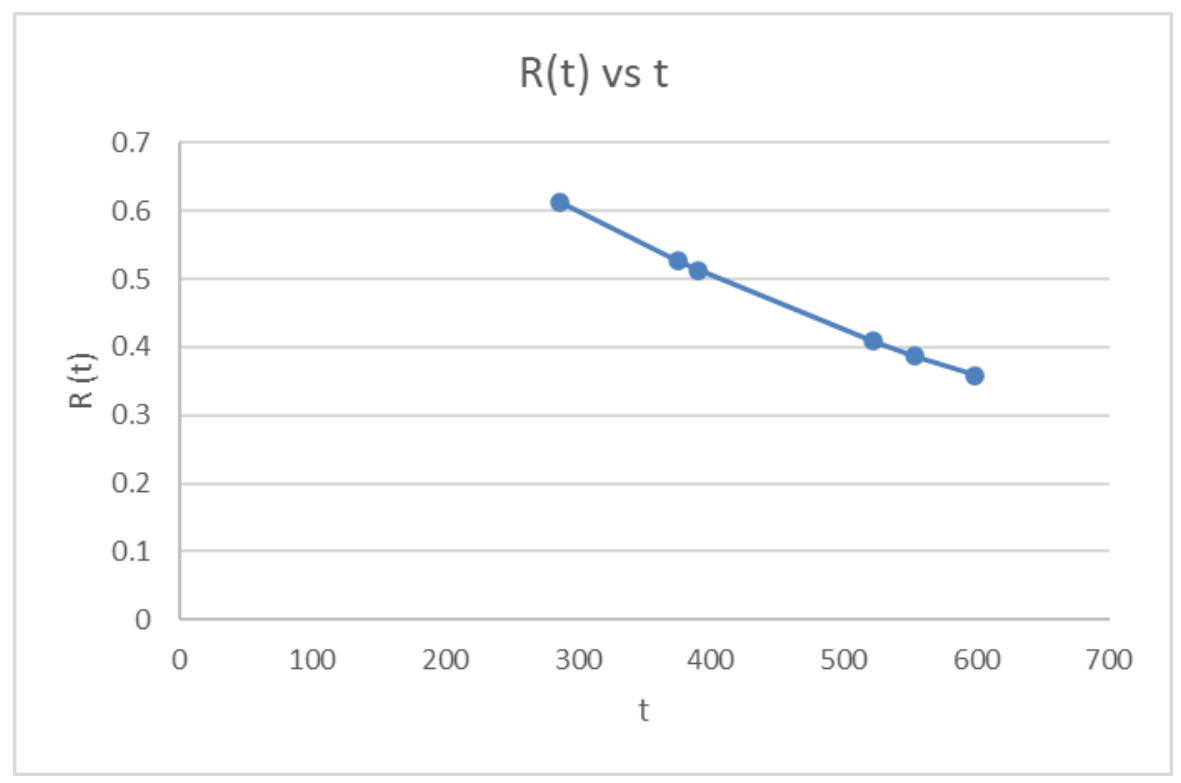

Gambar 2. Reliability vs Failure Time

Dari hasil pengolahan data usia komponen diperoleh nilai $\beta=3,810$ yang artinya karakeristik kegagalan yang terjadi adalah wear out, dan nilai $\mathrm{R}(\mathrm{t})$ yang terus mengalami penurunan seiring bertambahnya usia komponen. Hal ini sesuai dengan teori Bathtub Curve sebagaimana pada Gambar 3.

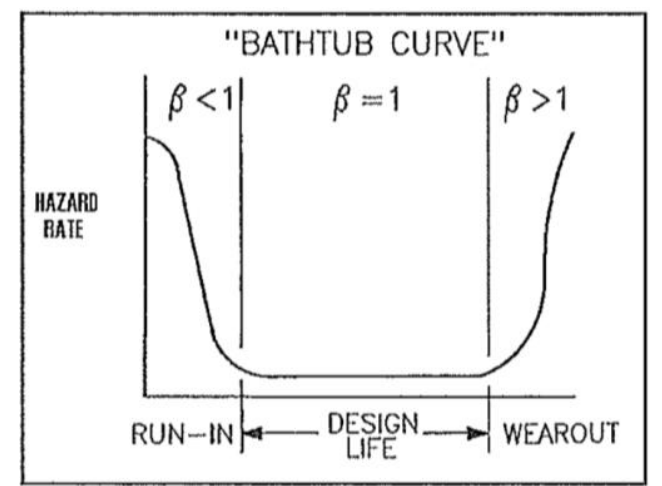

Gambar 3. Bathtub Curve Distribusi Weibull

(Sumber: Abernethy (2006))

Nose Wheel Assy yang digunakan pada pesawat ATR 72-500 merupakan nose wheel assy dengan part number : C20589000. Berdasarkan CMM (Component Maintenance Manual) nose wheel assy ini memiliki preventive maintenance Level 1 dan Level 2. Level 1 merupakan kegiatan perawatan yang bisa dilakukan dengan penerapan on condition dan Level 2 adalah scheduled maintenance yang merupakan kegiatan overhoul setelah penggantian tyre yang ke-5 [3]. Akan tetapi pada tabel 1 data kerusakan pada nose wheel assy adalah data unschedule maintenance karena kerusakan terjadi sebelum batas usia komponen. Jika kerusakan terjadi sebelum batas usia komponen akan menyebabkan terjadinya unscheduled maintenance, maka memerlukan upaya penanganan corrective maintenance [9]. Sehingga analisa keandalan ini dilakukan untuk mengantispasi agar dapat dilakukan pemantauan pada kondisi nose wheel assy sebelum mengalami kerusakan. 
Nose Wheel Assy memiliki peran dalam pergerakan pesawat terbang saat berada di darat seperti pergerakan taxing, landing, take off, dan parking. Sering terjadinya worn out pada nose wheel assy dapat disebabkan karena peran dari nose wheel assy yang salah satunya adalah menopang beban pesawat pada setiap pergerakan yang dilakukan. Sehingga kondisi worn out dapat terjadi. Salah satu komponen dalam nose wheel assy adalah tyre yang terdiri dari 2 (dua) tyre sebelah kanan dan kiri[3] . Tyre inilah yang sering kali mengalami indikasi kegagalan. Dari Tabel 1 dapat diketahui bahwa indikator kegagalan terjadi karena kondisi worn out. Worn out adalah kondisi dimana ditemukan spot pada tyre, deflated ataupun kondisi tyre yang sudah mengalami penipisan sehingga perlu dilakukan penggantian.

Hasil perhitungan dari data kerusakan selama Maret 2017 sampai Desember 2018, mean time to failure (MTTF) diperoleh nilai 454,014 hours. Nilai tersebut menunjukkan bahwa usia rata - rata komponen sampai dengan mengalami kegagalan adalah 454,014 hours. Maka data tersebut bisa dijadikan referensi untuk kegiatan condition monitoring pada nose wheel assy sehingga upaya perawatan bisa dilakukan dalam intensitas yang lebih sering. Karena untuk meningkatkan nilai reliability dibutuhkan waktu pengecekan dan perawatan yang lebih pendek sehingga mengurangi adanya kegagalan komponen dan membuat redundancy komponen [10]. Upaya preventive maintenance juga dapat dilakukan sebelum nose wheel assy mencapai usia 454,014 hours, sehingga dapat mencegah terjadinya kegagalan dan dapat meningkatkan keadalan dari komponen nose wheel assy.

\section{Kesimpulan}

Hasil pengolahan data kerusakan nose wheel assy dari Maret 2017 sampai Desember 2018 dengan distribusi weibull meyatakan bahwa keandalan komponen nose wheel assy menurun seiring dengan bertambahnya usia pemakaian dan diperoleh usia rata - rata komponen adalah 454,014 hours.

\section{Ucapan Terimakasih}

Ucapan terimakasih penulis sampaikan kepada P3M STT Adisutjipto yang telah berperan dalam memberikan bantuan dana dalam pelaksanaan penelitian ini.

\section{Daftar Pustaka}

[1] Abernethy R. B, 2006, The New Weibull Handbook, edisi ke5, North Palm Beach, Florida

[2] Astarini, L. A. A. D., \& Haryono, H. (2015). Analisis Reliabilitas Dan Availabilitas Pada Mesin Produksi Dengan Sistem Seri Menggunakan Pendekatan Analisis Markov Di Pt."X". Jurnal Sains dan Seni ITS, 4(1), D7-D12.

[3] Component Maintenance Manual With Illustrated Part List, Rev. N0.1, Messier Bugatti.

[4] Ebeling, C. E. (1997) An Introduction to Reliability \& Maintainability Engineering.

[5] Esa Ferraro. Kevin, 2019, Analisis Keandalan Landing GearPada Komponen Nose Wheel AssyATR 72-500 Menggunakan Distribusi Weibull, STT Adisutjipto, Yogyakarta.

[6] Kasiram, Moh, 2008, Metodologi Penelitian, Malang, UIN-Malang Pers.

[7] Kinnison A, Harry dan Siddiqui, T., 2004, Aviation Maintenance Manajemen 2nd Edition, The Mc Graw-Hill, New York.

[8] Praharsi, Y., Sriwana, I. K., \& Sari, D. M. (2015). Perancangan Penjadwalan Preventive Maintenance pada PT. Artha Prima Sukses Makmur. Jurnal Ilmiah Teknik Industri, 14(1), 59-65.

[9] Rahmawati, F. K. (2019). Inventory Planning Management Of Low Pressure Filter Web (LPFW) On KT1-BEE Aircraft Based On Reliability Component In SKATEK 043. Angkasa: Jurnal Ilmiah Bidang Teknologi, 11(2), 131-139.

[10] Rosihan, R. I. (2019). Analisis Sistem Reliability dengan Pendekatan Reliability Block Diagram. Jurnal Teknosains, 9(1).

[11] Saputra, D. R. F., Sukmono, Y., \& Fathimahhayati, L. D. (2018). Analisis Reliability Pada Mesin Fan Mill Unit 1 di PT Cahaya Fajar Kaltim. Dinamika: Jurnal Ilmiah Teknik Mesin, 10(1), 1-8.

[12] Utomo, M. N., \& Widjajati, F. A. (2014). Menentukan Keandalan Komponen Mesin Produksi Pada Model Stress Strength yang Berdistribusi Gamma. Jurnal Sains dan Seni ITS, 3(2), A22-A27.

[13] Yuhelson, Y., Syam, B., Sinullingga, S., \& Isranuri, I. (2010). Analisis Reliability Dan Availability Mesin Pabrik Kelapa Sawit Pt. Perkebunan Nusantara 3. Jurnal Dinamis, (6). 